\title{
Repeated Intraperitoneal $\alpha$-Radioimmunotherapy of Ovarian Cancer in Mice
}

\author{
Jörgen Elgqvist, ${ }^{1}$ Håkan Andersson, ${ }^{1}$ Holger Jensen, ${ }^{2}$ Helena Kahu, ${ }^{1}$ Sture Lindegren, ${ }^{1}$ \\ Elisabet Warnhammar, ${ }^{1}$ and Ragnar Hultborn ${ }^{1}$
}

${ }^{1}$ Institute of Clinical Sciences, The Sahlgrenska Academy, University of Gothenburg, 41345 Gothenburg, Sweden

${ }^{2}$ PET and Cyclotron Unit, Rigshospitalet, Copenhagen, Denmark

Correspondence should be addressed to Jörgen Elgqvist, jorgen.elgqvist@gu.se

Received 15 April 2009; Accepted 1 September 2009

Academic Editor: Maurie M. Markman

Copyright () 2010 Jörgen Elgqvist et al. This is an open access article distributed under the Creative Commons Attribution License, which permits unrestricted use, distribution, and reproduction in any medium, provided the original work is properly cited.

\begin{abstract}
The aim of this study was to investigate the therapeutic efficacy of $\alpha$-radioimmunotherapy of ovarian cancer in mice using different fractionated treatment regimens. The study was performed using the monoclonal antibody $\mathrm{MX} 35 \mathrm{~F}\left(\mathrm{ab}^{\prime}\right)_{2}$ labeled with the $\alpha$ particle emitter ${ }^{211}$ At. Methods. Nude mice were intraperitoneally inoculated with $\sim 1 \times 10^{7}$ cells of the cell line NIH:OVCAR-3. Four weeks later 6 groups of animals were given $400 \mathrm{kBq}{ }^{211} \mathrm{At}-\mathrm{MX} 35 \mathrm{~F}\left(\mathrm{ab}^{\prime}\right)_{2}$ as a single or as a repeated treatment of up to 6 times ( $n=18$ in each group). The fractionated treatments were given every seventh day. Control animals were treated with unlabeled $\mathrm{MX} 35 \mathrm{~F}\left(\mathrm{ab}^{\prime}\right)_{2}(n=12)$. Eight weeks posttreatment the animals were sacrificed and the presence of macro- and microscopic tumors and ascites was determined. Results. The tumor-free fractions (TFFs) of the animals, defined as the fraction of animals with no macro- and microtumors and no ascites, were $0.17,0.11,0.39,0.44,0.44$, and 0.67 when treated with $400 \mathrm{kBq}^{211} \mathrm{At}-\mathrm{MX}^{2} 5 \mathrm{~F}\left(\mathrm{ab}^{\prime}\right)_{2}$ once or 2, 3, 4, 5, or 6 times, respectively. Repeated treatment 3 times or more resulted in a significantly higher $(P<.05)$ TFF than compared to treatment once or twice. The presence of ascites decreased from 15 out of 18 animals in the group given only one treatment to zero for the 2 groups given 5 or 6 fractions. Treatment with unlabeled MX35 F $\left(\mathrm{ab}^{\prime}\right)_{2}$ resulted in a TFF of zero. Conclusion. Weekly repeated intraperitoneal injections of tolerable amounts of activity of ${ }^{211} \mathrm{At}-\mathrm{MX} 35 \mathrm{~F}\left(\mathrm{ab}^{\prime}\right)_{2}$ of up to 6 times produced increased therapeutic efficacy without observed toxicity, indicating a potential increase of the therapeutic index.
\end{abstract}

\section{Introduction}

Ovarian cancer frequently recurs on the peritoneal surface from remaining micrometastatic growth in spite of debulking surgery and systemic chemotherapy. External abdominal radiotherapy has proven unsuccessful due to absorbed dose limitations of normal tissues. Therefore, adjuvant locoregional treatment with intraperitoneal targeted ligands could be decisive in the treatment of remaining micrometastatic disease. Several studies have been performed on radioimmunotherapy (RIT) of ovarian cancer, mostly mAbs labeled with ${ }^{90} \mathrm{Y}$ and ${ }^{131} \mathrm{I}$, in animals [1-6] and humans [7-12]. The $\beta$-emitting radionuclides however have too long a range for effectively treating microscopic tumors. Thus we believe it is important to continue our investigations of the efficacy of mAbs labeled with $\alpha$-particle emitters when treating microscopic disease on the peritoneum [13]. In this study, as in a series of earlier studies [14-19], we used the $\alpha$ particle emitter ${ }^{211} \mathrm{At}$, with a half-life of 7.21 hours, a mean range in tissue of $\sim 62 \mu \mathrm{m}$, and a mean linear energy transfer (LET) of $\sim 111 \mathrm{keV} / \mu \mathrm{m}$. The half-life of this radionuclide makes it ideal for local treatment as the target cells are easily reached while the transfer of the radioimmunocomplex to the systemic circulation is delayed. The short range ensures a significant absorbed dose in microscopic tumors or even single cells. The high LET, together with the high relative biological effectiveness (RBE) of the $\alpha$-particles necessitating only a few hits to devitalize the cell, indicates that only a small number of ${ }^{211}$ At-atoms have to be targeted to each cell $[20,21]$.

In this study we used the monoclonal antibody ( $\mathrm{mAb}$ ) MX35 $\mathrm{F}\left(\mathrm{ab}^{\prime}\right)_{2}$, which recognizes the sodium dependant phosphate transport protein $2 \mathrm{~b}(\mathrm{NaPi} 2 \mathrm{~b})$ of $\sim 90 \mathrm{kDa}$ on ovarian cancer cells. We used an animal model mimicking 
the clinical situation with intraperitoneal RIT. The intraperitoneal approach allows a high absorbed dose to nonvascularized peritoneal tumor cells with low myelotoxicity as the clearance rate from the peritoneal cavity to the systemic circulation delays systemic exposure.

Fractionated external radiotherapy widens the therapeutic index compared to using a single fraction and higher absorbed doses can be delivered with acceptable toxicity. We hypothesize that this could be true for internal $\alpha$-RIT.

\section{Materials and Methods}

2.1. Radionuclide. ${ }^{211}$ At was produced by the ${ }^{209} \operatorname{Bi}(\alpha$, $2 \mathrm{n})^{211}$ At reaction in a cyclotron (Scanditronix MC32 at the PET and Cyclotron Unit, Rigshospitalet, Copenhagen, Denmark) by irradiating a ${ }^{209} \mathrm{Bi}$ target with $28 \mathrm{MeV} \alpha$ particles. The ${ }^{211} \mathrm{At}$ was isolated using a dry-distillation procedure [22].

2.2. Monoclonal Antibodies. MX35 is a murine IgG1-class $\mathrm{mAb}$, developed and characterized at the Memorial SloanKettering Cancer Center (MSKCC), Ny, USA. MX35 is directed towards the sodium dependant phosphate transport protein $2 \mathrm{~b}$ (NaPi2b) of $\sim 90 \mathrm{kDa}$ on OVCAR-3 cells [23] and is expressed strongly and homogeneously on $\sim 90 \%$ of human epithelial ovarian cancers [24]. A batch of MX35 $\mathrm{F}\left(\mathrm{ab}^{\prime}\right)_{2}$, produced by Strategic BioSolutions (Newark, USA) for clinical use, was provided by MSKCC.

2.3. Antibody Labeling. MAbs were labeled with ${ }^{211}$ At using the intermediate labeling reagent m-MeATE ( $N$ succinimidyl 3-(trimethylstannyl)benzoate) [25]. Briefly, to a dry residue of ${ }^{211}$ At (50-100 MBq) was added a mixture of m-MeATE and $\mathrm{N}$-iodosuccinimide in methanol: $1 \%$ acetic acid. This solution was then incubated for 20 minutes at room temperature and the labeling reaction was stopped by adding sodium ascorbate. The mAb MX35 F( $\left.\mathrm{ab}^{\prime}\right)_{2}$ was then added to the labeling mixture and conjugation was allowed to proceed for 20 minutes. Finally, the mAb fraction was isolated using a NAP-5 column (Amersham Biosciences, Uppsala, Sweden), resulting in a specific activity of $120 \mathrm{kBq} / \mu \mathrm{g}$, that is, 1 labeled mAb out of $\sim 1200 \mathrm{mAbs}$.

2.4. Cell Line. The cell line OVCAR-3 (NIH:OVCAR-3, ATCC, USA) was used [26]. The cell line was obtained from the American Type Culture Collection, Rockville, MD, USA. The cells were cultured in T-75 culture flasks at $37^{\circ} \mathrm{C}$ in a humidified atmosphere of $95 \% \mathrm{O}_{2} / 5 \% \mathrm{CO}_{2}$ with RPMI1640 cell culture medium supplemented with $10 \%$ fetal calf serum, $1 \% \mathrm{~L}$-glutamine, and $1 \%$ penicillin-streptomycin.

2.5. Immunoreactivity of Antibodies. After conjugation, the immunoreactivity of the mAbs was analyzed in vitro by determination of the immunoreactive fraction, representing conditions of infinite antigen excess, which was derived from a plot of the total applied radioactivity divided by cellbound radioactivity as a function of the inverse of the cell concentration [27].
2.6. Animals. We used 120 female, nude Balb/c nu/nu mice (Charles River Laboratories International Inc., Wilmington, MA, USA) in this study. The animals were housed at $22^{\circ} \mathrm{C}$ and $50 \%-60 \%$ humidity with a light/dark cycle of 12 hours. They were given autoclaved standard pellets and water ad libitum. All the experiments were approved by the Ethics Committee of the University of Gothenburg.

2.7. In Vivo Procedures and Study Groups. At the age of 5 weeks all mice were intraperitoneally inoculated with $\sim 1 \times 10^{7}$ OVCAR-3 cells suspended in $0.2 \mathrm{~mL}$ saline. Four weeks after cell inoculation the animals were divided into 7 groups. The animals in groups 1-6 were intraperitoneally injected with $400 \mathrm{kBq}{ }^{211} \mathrm{At}-\mathrm{MX} 35 \mathrm{~F}\left(\mathrm{ab}^{\prime}\right)_{2}$ in $1 \mathrm{~mL}$ saline as a single or as a weekly treatment of $2,3,4,5$, or 6 times, respectively ( $n=18$ in each group). As controls (group 7), animals were treated once with unlabeled MX35 $\mathrm{F}\left(\mathrm{ab}^{\prime}\right)_{2} \quad(n=12)$. All the animals were thereafter weighed weekly. Eight weeks after the last treatment occasion for each group the animals were sacrificed by cervical dislocation and dissected. The abdominal cavity was opened and the presence of ascites and macroscopic lesions was judged as "yes" or "no". Peritoneal biopsies were taken from the upper left quadrant since tumor propagation is most frequently seen in this area. Suspected lesions were also biopsied. All biopsies were processed for light microscopy and judged as "yes" or "no." Animals dissected and judged were blinded from knowledge of exposure conditions. Differences in TFF and weight between the different study groups were tested using a 2 -sample test for equality of proportions.

\section{Results}

The radiochemical yields were $30 \%-40 \%$ and the radiochemical purity was over $95 \%$ as determined by methanol precipitation and gel-permeability chromatography. The immunoreactivity measurements of the ${ }^{211}$ At-MX35 F $\left(\mathrm{ab}^{\prime}\right)_{2}$ and OVCAR-3 cells gave an immunoreactive fraction of 0.95 .

The TFFs of the study groups, defined as the fraction of animals with no macro- and microtumors and no ascites, were $0.17,0.11,0.39,0.44,0.44$, and 0.67 when treated with $400 \mathrm{kBq}{ }^{211} \mathrm{At}-\mathrm{MX} 35 \mathrm{~F}\left(\mathrm{ab}^{\prime}\right)_{2}$ as a single or as a repeated treatment regimen of $2,3,4,5$, or 6 times, respectively (Table 1). Repeated treatment of 3, 4, 5, or 6 times resulted in a significantly higher $(P<.05)$ TFF than that compared to 1 or 2 treatment. The presence of ascites decreased from 15 out of 18 animals in the group given only one treatment to zero for the 2 groups given 5 or 6 repeated treatments. The presence of tumors did not decrease as drastically as the presence of ascites when the number of treatments increased. Treatment with unlabeled MX35 $\mathrm{F}\left(\mathrm{ab}^{\prime}\right)_{2}$ resulted in a TFF of zero.

The findings on the peritoneal biopsies at the time of dissection revealed both larger tumor cell clusters of several millimetres in diameter as well as clusters consisting of only a few tumor cells. The tumor cells were sometimes only loosely adhered to the peritoneum but had sometimes penetrated under the mesothelial cell layer. 
TABLE 1: Study groups and number of mice with macroscopic and microscopic tumors and ascites.

\begin{tabular}{|c|c|c|c|c|c|c|c|}
\hline Group & $n$ & Treatment & Number of treatments & Macroscopic tumors & Microscopic tumors & Ascites & TFF $^{*}$ \\
\hline 1 & 18 & $400^{\dagger} \mathrm{kBq}^{211}$ At-MX35 $\mathrm{F}\left(\mathrm{ab}^{\prime}\right)_{2}$ in $\mathrm{PBS}^{\ddagger}$ & 1 & $11 / 18$ & $15 / 18$ & $15 / 18$ & 0.17 \\
\hline 2 & 18 & $400^{\dagger} \mathrm{kBq}^{211} \mathrm{At}-\mathrm{MX} 35 \mathrm{~F}\left(\mathrm{ab}^{\prime}\right)_{2}$ in $\mathrm{PBS}^{\ddagger}$ & 2 & $16 / 18$ & $16 / 18$ & $8 / 18$ & 0.11 \\
\hline 3 & 18 & $400^{\dagger} \mathrm{kBq}^{211}$ At-MX35 $\mathrm{F}\left(\mathrm{ab}^{\prime}\right)_{2}$ in $\mathrm{PBS}^{\ddagger}$ & 3 & $11 / 18$ & $11 / 18$ & $5 / 18$ & 0.39 \\
\hline 4 & 18 & $400^{\dagger} \mathrm{kBq}^{211}$ At-MX35 $\mathrm{F}\left(\mathrm{ab}^{\prime}\right)_{2}$ in $\mathrm{PBS}^{\ddagger}$ & 4 & $10 / 18$ & $10 / 18$ & $1 / 18$ & 0.44 \\
\hline 5 & 18 & $400^{\dagger} \mathrm{kBq}^{211}$ At-MX35 $\mathrm{F}\left(\mathrm{ab}^{\prime}\right)_{2}$ in $\mathrm{PBS}^{\ddagger}$ & 5 & $10 / 18$ & $10 / 18$ & $0 / 18$ & 0.44 \\
\hline 6 & 18 & $400^{\dagger} \mathrm{kBq}^{211} \mathrm{At}-\mathrm{MX} 35 \mathrm{~F}\left(\mathrm{ab}^{\prime}\right)_{2}$ in $\mathrm{PBS}^{\ddagger}$ & 6 & $6 / 18$ & $6 / 18$ & $0 / 18$ & 0.67 \\
\hline 7 & 12 & MX35 F $\left(\mathrm{ab}^{\prime}\right)_{2}$ in PBS & 1 & $12 / 12$ & $12 / 12$ & $10 / 12$ & 0 \\
\hline
\end{tabular}

* TFF : tumor-free fraction (i.e., fraction of animals with no macro- and microscopic tumors and no ascites). Injected activities were ${ }^{\dagger} 400 \pm 14 \mathrm{kBq}(\mathrm{mean}$ \pm SEM). ${ }^{\ddagger}$ PBS : phosphate-buffered saline. The presence of macroscopic tumors and ascites was assesed by careful ocular inspection during dissection 2 mo after the last administration of the radioimmunocomplex. Microscopic tumor growth was assessed by conventional histopathology. Judgements were blinded from treatment information.

The general condition of the animals seemed to be unaffected by the different treatment regimens, although the weights of the control animals were significantly higher $(P$ $<.05)$ than those of the animals given different regimens of ${ }^{211}$ At-MX35 $\mathrm{F}\left(\mathrm{ab}^{\prime}\right)_{2}$ (groups 1-6), due to the ascites production. No mutually significant difference $(P>0.5)$ in weight between the groups given different regimens of ${ }^{211} \mathrm{At}$ MX35 $\mathrm{F}\left(\mathrm{ab}^{\prime}\right)_{2}$ could be detected and no deaths occurred during followup.

\section{Discussion}

Fractionated radiotherapy in humans results in an increased therapeutic efficacy as compared to single doses and allows for increased total absorbed dose delivered to the target area. Mimicking such fractionation using RIT presents challenges with respect to physical half-lives and biodistribution. Reasons why fractionated RIT would appear promising are the possibility of reducing the systemic toxicity and hence increasing the maximum tolerated activity, achieving a more uniform absorbed dose distribution in the tumor, and increasing the therapeutic index. We have in a previous animal study found significantly less myelotoxicity dividing the injected activity into 3 fractions, with only a minor decrease in therapeutic efficacy [28]. In that study we also discussed the potential risk of treatment interruption in the human situation due to human antimouse antibody (HAMA) response. However, in our recently published phase I study in which we used a fragmented IgG1 mAb $\left(\mathrm{MX} 35 \mathrm{~F}\left(\mathrm{ab}^{\prime}\right)_{2}\right)$ we could not detect any signs of any HAMA response, indicating a low probability for an HAMA responses in potential future fractionated clinical RIT treatments [29]. In the present study we chose an activity well tolerated as a single injection $(400 \mathrm{kBq})$, with a white blood cell recovery approximately within a week, to be repeated weekly for up to 6 times, that is, a total activity of up to $2400 \mathrm{kBq}$, not tolerated as a single injection [20]. An interval of 7 days was chosen from the bone marrow recovery data [28] as well as from logistics, that is, a weekly delivery of ${ }^{211}$ At. The rationale for choosing the fragmented $\mathrm{mAb}$ instead of the whole IgG in this study is due to 4 facts. (i) The fragmented $\mathrm{mAb}$ was the only clinical grade version of the $\mathrm{mAb}$ available at the time of the study; (ii) we have received an approval by the Swedish Medical Products Agency for carry through a phase I study with this fragmented mAb; (iii) we believe that the diffusion into tumors using the fragmented $\mathrm{mAb}$ is higher than compared to whole IgG; (iv) We believe that the immunogenicity of the fragmented $\mathrm{mAb}$ is lower than the whole $\operatorname{IgG}$, reducing the risk for HAMA response, especially if repeated treatments are considered in the future.

In the series of experiments in this paper the efficacy expressed as the tumor-free fraction (TFF) was less than in previous studies from our group [14-19], but a significant total activity and TFF relation were shown without any signs of toxicity. The difference in the efficacy between the studies probably reflects varying proliferation of the injected cells resulting in different sizes of the tumor deposits at the time of treatment, that is, 4 weeks postinjection. Since the $\alpha$-particle track length is limited to $60-70 \mu \mathrm{m}$ the size of the tumor cell clusters is crucial. In an earlier study [19] tumor dimensions were measured and the largest clusters at 4 weeks postinoculation were $\sim 95 \mu \mathrm{m}$, actually exceeding the $\alpha$-particle path length. A significant peeling of the outermost cell layers of the tumor cell clusters and/or a uniform absorbed dose distribution does not seem probable since $\sim 1 / 3$ of the animals were not free of tumors in spite of up to 6 treatment fractions. In the interval of $400-1200 \mathrm{kBq}$ in our earlier preclinical studies the TFF was not correlated with the administered activity. This could be explained by the saturation of the antigenic sites, which-according to the dynamic compartmental model introduced in one of those studies [17] — occurs within a few hours after the injection, resulting in a similar absorbed dose for those activity levels.

In our recently published phase I study on women in clinical complete remission after ovarian cancer occurrence we disclosed no marrow toxicity after an intraperitoneal injection of $\sim 200 \mathrm{MBq}{ }^{211} \mathrm{At}-\mathrm{MX} 35 \mathrm{~F}\left(\mathrm{ab}^{\prime}\right)_{2}$ in $1 \mathrm{~L}$, which is in accordance with a low absorbed dose to the bone marrow derived from biokinetic data [29]. This, together with a low probability for HAMA response discussed above, could indicate a possibility of using a fractionated regimen in a phase II study now under planning.

In conclusion, weekly repeated intraperitoneal injections of tolerable amounts of activity of ${ }^{211} \mathrm{At}-\mathrm{MX} 35 \mathrm{~F}\left(\mathrm{ab}^{\prime}\right)_{2}$ of up to 6 times produced increased efficacy without observed 
toxicity, indicating a potential increase of the therapeutic index.

\section{Acknowledgments}

This work was conducted at The Sahlgrenska Academy at the University of Gothenburg and was supported by grants from the Swedish Cancer Society (no. 3548) and the King Gustaf V Jubilee Clinic Research Foundation in Gothenburg, Sweden.

\section{References}

[1] S. A. McQuarrie, J. R. Mercer, A. Syme, M. R. Suresh, and G. G. Miller, "Preliminary results of nanopharmaceuticals used in the radioimmunotherapy of ovarian cancer," Journal of Pharmacy \& Pharmaceutical Sciences, vol. 7, pp. 29-34, 2004.

[2] M. L. Janssen, W. Pels, L. F. Massuger, et al., "Intraperitoneal radioimmunotherapy in an ovarian carcinoma mouse model: effect of the radionuclide," International Journal of Gynecological Cancer, vol. 13, no. 5, pp. 607-613, 2003.

[3] P. E. Borchardt, S. M. Quadri, R. S. Freedman, and H. M. Vriesendorp, "Intraperitoneal radioimmunotherapy with human monoclonal IGM in nude mice with peritoneal carcinomatosis," Cancer Biotherapy and Radiopharmaceuticals, vol. 15 , no. 1, pp. 53-64, 2000.

[4] C. Grana, M. Bartolomei, D. Handkiewicz, et al., "Radioimmunotherapy in advanced ovarian cancer: is there a role for pre-targeting with ${ }^{90}$ Y-biotin?" Gynecologic Oncology, vol. 93, no. 3, pp. 691-698, 2004.

[5] R. F. Meredith, R. D. Alvarez, E. E. Partridge, et al., "Intraperitoneal radioimmuno-chemotherapy of ovarian cancer: a phase I study," Cancer Biotherapy and Radiopharmaceuticals, vol. 16, pp. 305-315, 2001.

[6] M.-A. Mahe, P. Fumoleau, M. Fabbro, et al., "A phase II study of intraperitoneal radioimmunotherapy with iodine131-labeled monoclonal antibody OC-125 in patients with residual ovarian carcinoma," Clinical Cancer Research, vol. 5, no. 10, supplement, pp. 3249-3253, 1999.

[7] A. A. Epenetos, V. Hird, H. Lambert, P. Mason, and C. Coulter, "Long term survival of patients with advanced ovarian cancer treated with intraperitoneal radioimmunotherapy," International Journal of Gynecological Cancer, vol. 10, supplement 1, pp. 44-46, 2000.

[8] R. D. Alvarez, E. E. Partridge, M. B. Khazaeli, et al., "Intraperitoneal radioimmunotherapy of ovarian cancer with ${ }^{177} \mathrm{Lu}-$ CC49: a phase I/II study," Gynecologic Oncology, vol. 65, no. 1, pp. 94-101, 1997.

[9] R. D. Alvarez, W. K. Huh, M. B. Khazaeli, et al., "A phase I study of combined modality ${ }^{90}$ Yttrium-CC49 intraperitoneal radioimmunotherapy for ovarian cancer," Clinical Cancer Research, vol. 8, no. 9, pp. 2806-2811, 2002.

[10] J. S. W. Stewart, V. Hird, D. Snook, et al., "Intraperitoneal yttrium-90-labeled monoclonal antibody in ovarian cancer," Journal of Clinical Oncology, vol. 8, no. 12, pp. 1941-1950, 1990.

[11] R. H. Verheijen, L. F. Massuger, B. B. Benigno, et al., "Phase III trial of intraperitoneal therapy with yttrium-90labeled HMFG1 murine monoclonal antibody in patients with epithelial ovarian cancer after a surgically defined complete remission," Journal of Clinical Oncology, vol. 24, no. 4, pp. 571$578,2006$.
[12] A. L. Oei, R. H. Verheijen, M. V. Seiden, et al., "Decreased intraperitoneal disease recurrence in epithelial ovarian cancer patients receiving intraperitoneal consolidation treatment with yttrium-90-labeled murine HMFG1 without improvement in overall survival," International Journal of Cancer, vol. 120, no. 12, pp. 2710-2714, 2007.

[13] H. Andersson, J. Elgqvist, G. Horvath, et al., "Astatine-211labeled antibodies for treatment of disseminated ovarian cancer: an overview of results in an ovarian tumor model," Clinical Cancer Research, vol. 9, no. 10, pp. 3914-3921, 2003.

[14] H. Andersson, S. Lindegren, T. Bäck, L. Jacobsson, G. Leser, and G. Horvath, "Radioimmunotherapy of nude mice with intraperitoneally growing ovarian cancer xenograft utilizing ${ }^{211}$ At-labelled monoclonal antibody MOv18," Anticancer Research, vol. 20, no. 1, pp. 459-462, 2000.

[15] H. Andersson, S. Lindegren, T. Bäck, L. Jacobsson, G. Leser, and G. Horvath, "The curative and palliative potential of the monoclonal antibody MOv18 labelled with ${ }^{211}$ At in nude mice with intraperitoneally growing ovarian cancer xenografts: a long-term study," Acta Oncologica, vol. 39, no. 6, pp. 741-745, 2000.

[16] H. Andersson, S. Palm, S. Lindegren, et al., "Comparision of the therapeutic efficacy of ${ }^{211}$ At- and ${ }^{131}$ I-labelled monoclonal antibody MOv18 in nude mice with intraperitoneal growth of human ovarian cancer," Anticancer Research, vol. 21, no. 1, pp. 409-412, 2001.

[17] J. Elgqvist, H. Andersson, T. Bäck, et al., "Therapeutic efficacy and tumor dose estimations in radioimmunotherapy of intraperitoneally growing OVCAR-3 cells in nude mice with ${ }^{211}$ At- labeled monoclonal antibody MX35," Journal of Nuclear Medicine, vol. 46, no. 11, pp. 1907-1915, 2005.

[18] J. Elgqvist, H. Andersson, P. Bernhardt, et al., "Administered activity and metastatic cure probability during radioimmunotherapy of ovarian cancer in nude mice with ${ }^{211}$ At-MX35F( $\left(\mathrm{ab}^{\prime}\right)_{2}$," International Journal of Radiation Oncology Biology Physics, vol. 66, no. 4, pp. 1228-1237, 2006.

[19] J. Elgqvist, H. Andersson, T. Bäck, et al., “ $\alpha$ radioimmunotherapy of intraperitoneally growing OVCAR-3 tumors of variable dimensions: outcome related to measured tumor size and mean absorbed dose," Journal of Nuclear Medicine, vol. 47, no. 8, pp. 1342-1350, 2006.

[20] J. Elgqvist, P. Bernhardt, R. Hultborn, et al., "Myelotoxicity and RBE of ${ }^{211}$ At-conjugated monoclonal antibodies compared with ${ }^{99 \mathrm{~m}} \mathrm{Tc}$-conjugated monoclonal antibodies and ${ }^{60} \mathrm{Co}$ irradiation in nude mice," Journal of Nuclear Medicine, vol. 46, no. 3, pp. 464-471, 2005.

[21] T. Bäck, H. Andersson, C. R. Divgi, et al., "211At radioimmunotherapy of subcutaneous human ovarian cancer xenografts: evaluation of relative biologic effectiveness of an $\alpha$-emitter in vivo," Journal of Nuclear Medicine, vol. 46, no. 12, pp. 2061-2067, 2005.

[22] S. Lindegren, T. Bäck, and H. J. Jensen, "Dry-distillation of astatine-211 from irradiated bismuth targets: a time-saving procedure with high recovery yields," Applied Radiation and Isotopes, vol. 55, no. 2, pp. 157-160, 2001.

[23] B. W. Yin, R. Kiyamova, R. Chua, et al., "Monoclonal antibody MX35 detects the membrane transporter NaPi2b (SLC34A2) in human carcinomas," Cancer Immunity, vol. 8, pp. 3-11, 2008.

[24] S. C. Rubin, L. Kostakoglu, C. Divgi, et al., "Biodistribution and intraoperative evaluation of radiolabeled monoclonal antibody MX 35 in patients with epithelial ovarian cancer," Gynecologic Oncology, vol. 51, no. 1, pp. 61-66, 1993. 
[25] S. Lindegren, H. Andersson, T. Bäck, L. Jacobsson, B. Karlsson, and G. Skarnemark, "High-efficiency astatination of antibodies using $\mathrm{N}$-iodosuccinimide as the oxidising agent in labelling of N-succinimidyl 3-(trimethylstannyl)benzoate," Nuclear Medicine and Biology, vol. 28, no. 1, pp. 33-39, 2001.

[26] T. C. Hamilton, R. C. Young, W. M. McKoy, et al., "Characterization of a human ovarian carcinoma cell line (NIH:OVCAR3 ) with androgen and estrogen receptors," Cancer Research, vol. 43, no. 11, pp. 5379-5389, 1983.

[27] T. Lindmo, E. Boven, F. Cuttitta, J. Fedorko, and P. A. Bunn, "Determination of the immunoreactive fraction of radiolabeled monoclonal antibodies by linear extrapolation to binding at infinite antigen excess," Journal of Immunological Methods, vol. 72, no. 1, pp. 77-89, 1984.

[28] J. Elgqvist, H. Andersson, T. Bäck, et al., "Fractionated radioimmunotherapy of intraperitoneally growing ovarian cancer in nude mice with ${ }^{211} \mathrm{At}-\mathrm{MX} 35 \mathrm{~F}\left(\mathrm{ab}^{\prime}\right)_{2}$ : therapeutic efficacy and myelotoxicity," Nuclear Medicine and Biology, vol. 33, no. 8, pp. 1065-1072, 2006.

[29] H. Andersson, E. Cederkrantz, T. Bäck, et al., "Intraperitoneal $\alpha$-particle radioimmunotherapy of ovarian cancer patients: pharmacokinetics and dosimetry of ${ }^{211} \mathrm{At}-\mathrm{MX} 35 \mathrm{~F}\left(\mathrm{ab}^{\prime}\right)_{2}-\mathrm{a}$ phase I study," Journal of Nuclear Medicine, vol. 50, no. 7, pp. 1153-1160, 2009. 


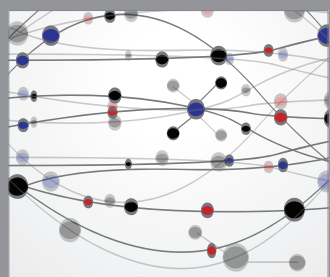

The Scientific World Journal
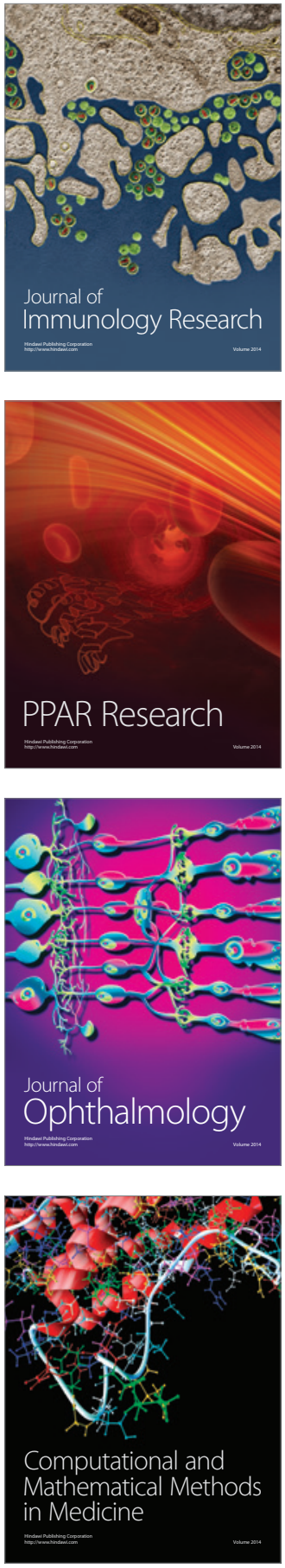

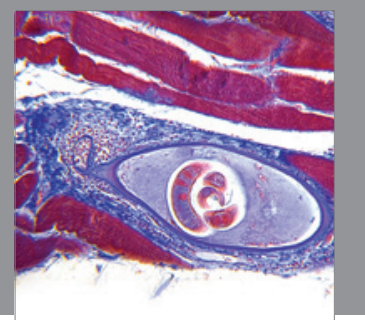

Gastroenterology

Research and Practice
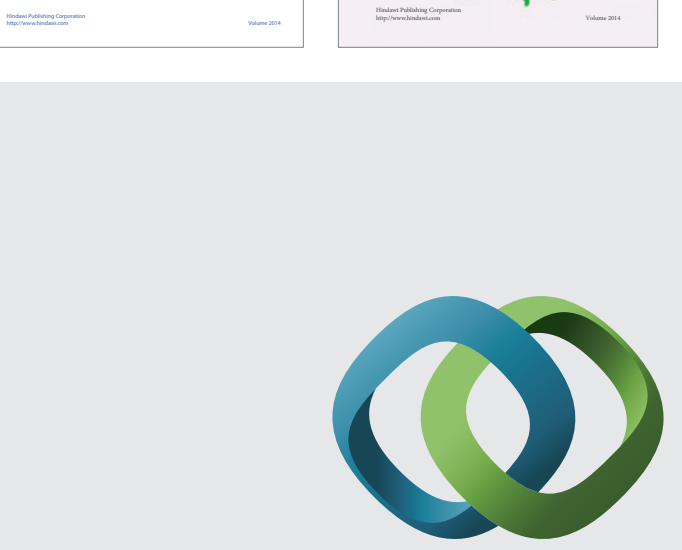

\section{Hindawi}

Submit your manuscripts at

http://www.hindawi.com
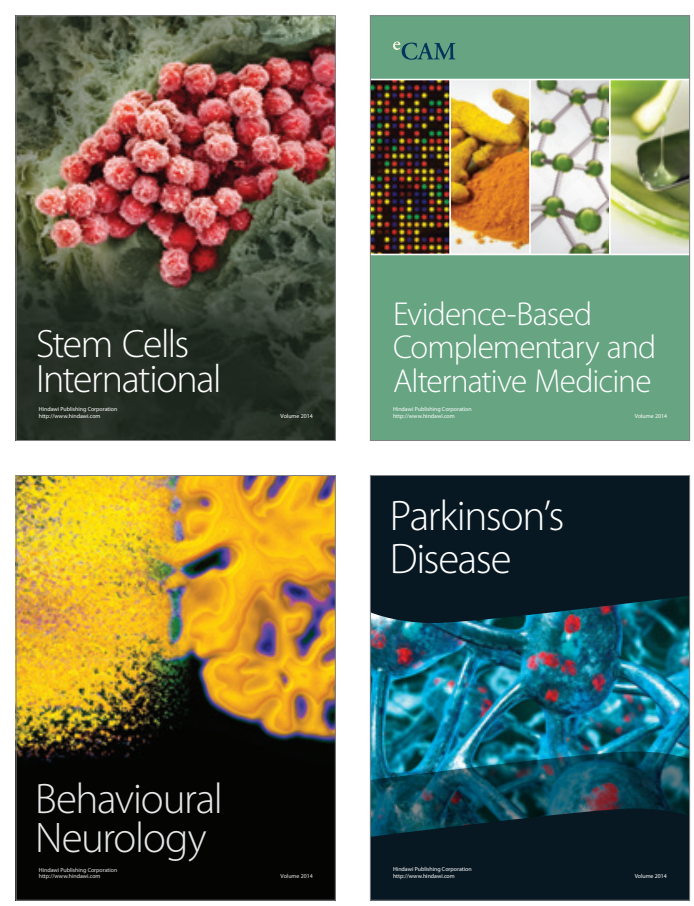

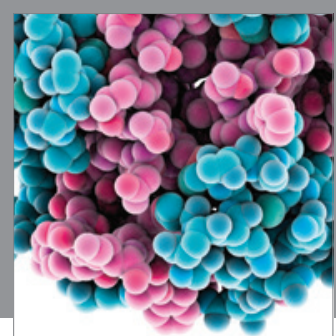

Journal of
Diabetes Research

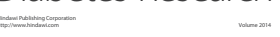

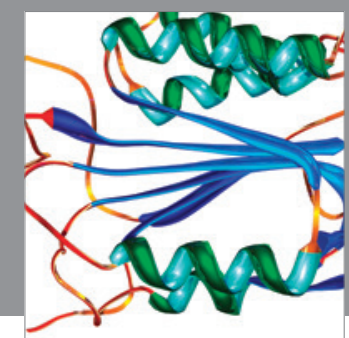

Disease Markers
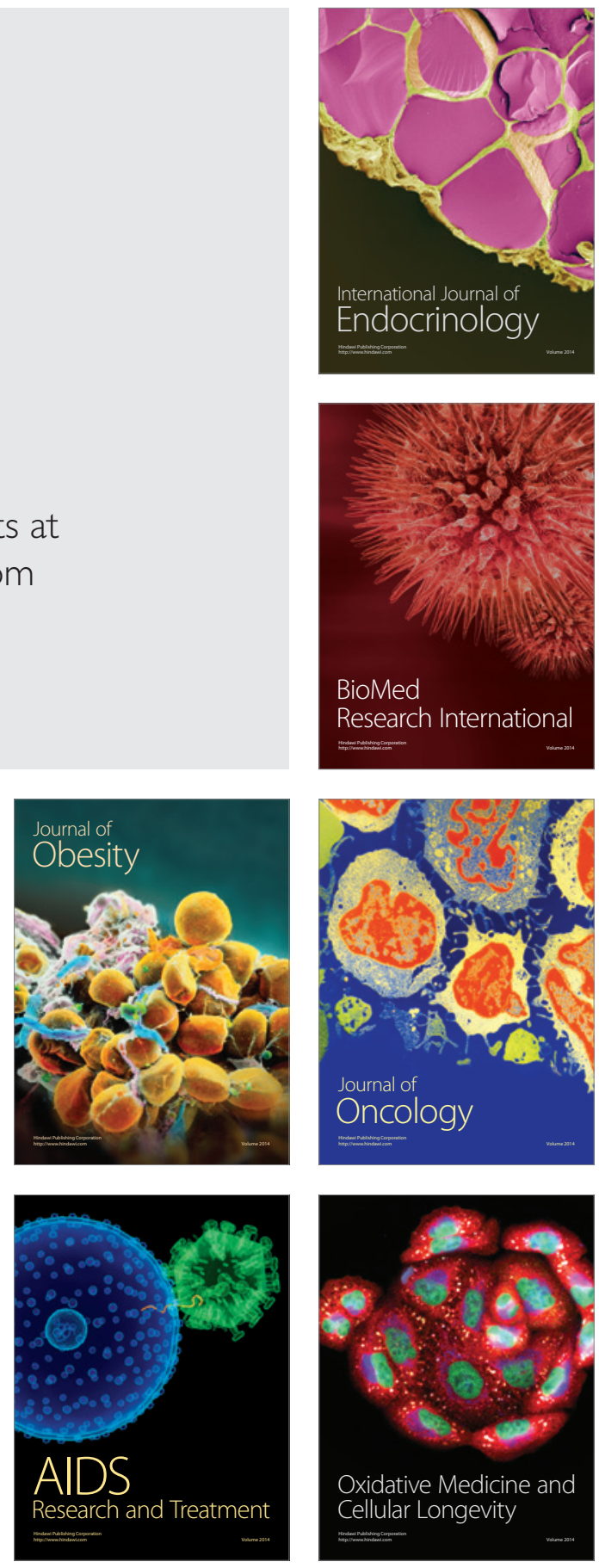